\title{
Investigar y enseñar historia \\ en perspectiva feminista decolonial ${ }^{*}$
}

\author{
Researching and teaching history \\ in decolonial feminist perspective
}

\author{
Lissell Quiroz $^{* *}$
}

Recibido: 20 de septiembre de 2019 Aceptado: 10 de noviembre de 2020 Publicado: 31 de julio de 2020

To cite this article: Quiroz, L. (2020). Investigar y enseñar historia en perspectiva feminista decolonial. Márgenes, Revista de Educación de la Universidad de Málaga, 1 (2), 138-152

DOI: https://doi.org/10.24310/mgnmar.v1i2.6786

\section{RESUMEN}

El artículo analiza la manera de escribir y enseñar la historia desde una perspectiva feminista decolonial. Esta teoría, desarrollada por activistas del sur global tales como Ochy Curiel o Yuderkys Espinosa, propone no solo conceptualizar el entramado de opresiones en el que se encuentran las mujeres subalternas, sino también una praxis original. Partiendo de esas teorizaciones, el artículo expone la manera en que la autora las aplica en su trabajo como historiadora y en su práctica como docente en el departamento de estudios hispánicos en Francia. La primera parte, que a la investigación se refiere, se centra en la historia de la maternidad en clave decolonial examinando el nacimiento como un espacio de poder en el que se imbrican diferentes sistemas de opresión (de clase, raza, y sexo/género). Por otra parte, el estudio presenta diferentes experiencias de descolonización del saber en el ámbito universitario francés.

Palabras clave: historia; estudios decoloniales; feminismo; enseñanza; universidad

\section{ABSTRACT}

The article analyzes the way of writing and teaching history from a decolonial feminist perspective. This theory, developed by activists from the global south such as Ochy Curiel or Yuderkys Espinosa, proposes not only to conceptualize the web of oppressions in which subaltern women are found, but also an original praxis. Starting from these theorizations, the article exposes the way in which the author applies them in her work as a historian and in her practice as a teacher in the department of Hispanic studies in France. As far as research is concerned, the history of maternity in decolonial key examines birth as a space of power in which different systems of oppression (of class, race, and sex / gender) are interwoven. On the other hand, the study presents different experiences of decolonization of knowledge in the French university environment.

Keywords: history; decolonial studies; feminism; teaching; university

* Utilizadora del lenguaje incluyente desde hace varios años, he ido variando las formas de escribirlo, empleando algunas veces la @, la X o la grafía o/a. La primera forma tiene tendencia a desaparecer mientras que la segunda la ha suplantando en algunas formas escritas. En cuanto a la forma a/o acentúa e institucionaliza por escrito el binarismo de género. Por eso algunas personas que no se reconocen ni en el género masculino ni femenino rechazan esta forma de escribir y prefieren las formas neutras. Las tres terminaciones plantean el problema de la pronunciación oral. Por eso, algunos sectores del feminismo argentino han propuesto desde hace más de un año, la neutralización del género mediante la utilización de la terminación en "e" (como diputade). He optado por emplear esta variante del lenguaje inclusivo porque me parece que no dificulta la lectura y evita a la vez la formalización del binarismo de género. 


\section{INTRODUCCIÓN}

Si no trabajamos para crear un movimiento de masas que ofrezca una educación feminista a todo el mundo, mujeres y hombres, la información negativa producida en la mayoría de los principales medios de comunicación de masas seguirá desvirtuando la teoría y la práctica feminista. Es imposible que la ciudadanía de este país llegue a conocer las contribuciones positivas que ha generado el movimiento feminista en todas nuestras vidas si no destacamos estos logros. La cultura dominante a menudo se apropia de las contribuciones feministas al bienestar de nuestras comunidades y nuestra sociedad y después proyecta representaciones negativas del feminismo. La mayoría de la gente no entiende las innumerables maneras en las que el feminismo ha cambiado todas nuestras vidas de forma positiva. Compartir el pensamiento y la práctica feminista sostiene al movimiento feminista. Los saberes feministas son para todo el mundo (hooks, 2007, pp. 46).

En esta cita como en otros escritos, bell hooks recalca que la investigación feminista no debe quedarse en un perímetro exclusivamente académico sino abrirse al público en general. En diálogo con las producciones artísticas, pedagógicas y teóricas del Black feminism, las feministas decoloniales de Abya Yala ${ }^{1}$ lamentan, como sus compañeras del norte del continente, que el feminismo hegemónico se haya institucionalizado en la universidad desconectándose al mismo tiempo de las márgenes de donde surgió (Lugones, 2011). Es cierto que en muchos países, las historias del feminismo que se vienen escribiendo desde los años ochenta se focalizan en las producciones teóricas y en las acciones de las mujeres occidentales de clases medias y altas. Pocos trabajos resaltan en cambio los aportes epistemológicos y las acciones de gran valor de las mujeres subalternas. Comparto ampliamente esa perspectiva y considero que es indispensable que los saberes feministas circulen mejor entre la universidad y los demás sectores sociales, sobre todo los más marginalizados. Estas reflexiones invitan a (re)pensar nuestra postura epistemológica y nuestras prácticas en tanto que investigadoras y docentes feministas.

En ese sentido, tal como lo señala Yuderkys Espinosa, el feminismo decolonial es una apuesta epistémica que cuestiona las teorías y propuestas más visibilizadas del feminismo y que “elabora una genealogía del pensamiento producido desde los márgenes” (Espinosa-Miñoso, 2014, pp. 7). Las feministas decoloniales de Abya Yala confeccionan una cartografía de los saberes propia y en diálogo con epistemologías críticas producidas en otros espacios geográficos. Esta apuesta implica descentrar los saberes hegemónicos y proponer otras maneras de ver y comprender el mundo.

El artículo presenta el interés de articular los planteamientos feministas decoloniales en la investigación y la enseñanza de la historia. Esta disciplina no ha sido muy receptiva a las propuestas decoloniales, contrariamente a otras ciencias humanas como la filosofía o la sociología. Esto se debe en parte a la posición central de las fuentes escritas en el trabajo histórico. Las historiadoras feministas señalan desde los años setenta la dificultad de escribir una historia de las

1 Abya Yala es un vocablo del pueblo originario kuna, residente en los actuales territorios de Colombia y Panamá, empleado para designar el continente americano. Numerosas organizaciones de pueblos originarios, así como activistas y universitarios lo prefieren al nombre colonial de América que invisibilizó todas las demás formas de nombrar a la región antes de la llegada de Cristóbal Colón. 
mujeres a partir de los archivos históricos tal y como han sido constituidos desde su fundación (Perrot, 2006). Y es que, como lo señala Gayatri C. Spivak, les subalternes no "hablan” a través de las fuentes documentales sino que casi siempre son "hablades" por los que escribieron la historia, desde el prisma del poder (Spivak, 1988). Mis investigaciones sobre la historia de la maternidad en el Perú de los siglos XIX y XX me han invitado a reevaluar la forma de movilizar las fuentes y a reelaborar el marco teórico de este tema para proponer una historia del nacimiento que tomara en cuenta la imbricación de los parámetros de clase, raza y sexo.

El artículo aquí propuesto aborda esta problemática a partir de mi propia experiencia como historiadora y profesora de estudios latinoamericanos Francia. Para tratar esta temática se abordarán tres puntos. La primera parte presenta el contexto de enunciación de este estudio. La segunda platea más en detalle las orientaciones de mis investigaciones en lo que concierne la historia de la maternidad y de los feminismos de Abya Yala. En última instancia se evocan algunas pistas y propuestas pedagógicas para la enseñanza en clave feminista decolonial.

\section{CONTEXTUALIZACIÓN Y LUGAR DE ENUNCIACIÓN}

Para entender mejor la experiencia descrita en estas páginas, es preciso presentar el contexto en el que ésta se desarrolla y el lugar de enunciación desde donde se escribe esta historia. Les pensadores postcoloniales y decoloniales han hecho una crítica de la posición de poder adoptada por la ciencia occidental moderna. Santiago Castro-Gómez muestra cómo los ilustrados neogranadinos del siglo XVIII se posicionaron en lo que él llama "el punto cero", es decir "una plataforma neutra de observación que, a su vez, no puede ser observada desde ningún punto" (Castro-Gómez, 2005, pp. 18). Situarse en el punto cero significa considerarse en un lugar neutro, distante del objeto de estudio, y que otorga a los que allí se sitúan, un privilegio epistémico que lleva el nombre de cientificidad. Ese es el modelo cartesiano del cual se reclaman todas las ciencias duras, humanas y sociales, entre las cuales figura la historia. Esto se observa claramente por ejemplo en las bases de la Escuela metódica francesa del siglo XIX impulsada por Gabriel Monod, Charles-Victor Langlois y Charles Seignobos. La situación en el punto cero otorga el privilegio epistémico de no interrogarse sobre su lugar de enunciación por considerarlo como neutro y universal. En realidad todas las personas nos expresamos en función de nuestra historia, nuestra ubicación geográfica y nuestra socialización de clase y de género. Por ende, el aparente no-lugar desde donde se sitúa ciencia moderna constituye en sí mismo una posición situada (Mignolo, 2003, pp. 39). La conciencia del lugar de enunciación de cada persona no es sin embargo un freno al conocimiento ni a la producción de saberes. Ser consciente de su posición de poder constituye más bien un primer paso para deshacer la jerarquía constitutiva del pensamiento eurocentrado y aceptar que diversas formas de concebir el mundo y nuestro pasado son válidas y legítimas aunque no emanen de la universidad ni de los círculos intelectuales con mayor prestigio.

En lo que a mí respecta, soy historiadora especializada en estudios latinoamericanos formada en Francia. Por otro lado soy migrante racializada de origen peruano y popular. En la jerga sociológica soy lo que se conoce con el término de "tránsfuga de clase” o "transclase” (Jaquet, 2015). Me sitúo en la vertiente del "pensamiento fronterizo" (Anzaldúa, 1987), es decir en ese lugar de 


\section{E X P E R I E N C I A S}

confluencia de diferentes epistemologías y cosmovisiones. En mi caso, se trata del espacio andino quechua y aimara, la Lima migrante y el norte de Francia, lugares entre los que circulo y he circulado mucho.

Desde 2011, soy docente titular de historia de América Latina en el Departamento de Estudios Románicos en una universidad francesa. Hay que precisar que en Francia la investigación y la enseñanza de las culturas "hispánicas” están englobadas bajo el término de hispanismo. Éste posee caracteres específicos derivados de la historia y de los vínculos entre Francia y España. No es por ello de extrañar que el sur de Francia -y principalmente en las regiones limítrofes con España como son las academias de Tolosa y Burdeos² ${ }^{2}$ haya sido la cuna de los estudios hispánicos. De hecho en las regiones cercanas a los Pirineos se estudia el español como primera lengua extranjera. La primera cátedra francesa de lengua y literatura españolas se creó en la universidad de Tolosa en 1886 y la segunda lo fue en Burdeos en 1898 (Cirot, 1899). Durante su primer siglo de existencia, los estudios hispánicos van a centrarse principalmente en la investigación y la enseñanza de la literatura y la lengua españolas. Paralelamente, las relaciones entre Francia y España se intensifican durante la primera mitad del siglo XX, sobre todo con la llegada de miles refugiados españoles que huían de la Guerra civil (1936-1939) y posteriormente del régimen franquista. En esta primera fase, América Latina no figuraba en los programas de estudios en tanto que les profesores de los departamentos de estudios hispánicos eran principalmente franceses.

Las relaciones entre Francia y América Latina son de otra índole. Francia buscó situarse, desde mediados del siglo XIX, como una alternativa a la supremacía española y estadounidense en el continente americano. Por esa razón adoptó y difundió la expresión "América Latina" (en vez de Hispanoamérica o Iberoamérica) que prevalece hasta hoy para designar a todos los países situados al sur de los Estados Unidos. En las primeras décadas del siglo XX, Francia intentó reforzar sus relaciones con los países latinoamericanos. El gobierno francés creó así en 1908 el Groupement des universités et grandes écoles de France pour les relations avec l'Amérique latine (Agrupación universitaria en pro de las relaciones con América Latina). Esta agrupación de cooperación universitaria francesa tenía como objetivo valorizar la investigación sobre América Latina desde Francia y difundir en esa región el pensamiento, los métodos y los saberes franceses (Huerta 2013). No obstante, los estudios latinoamericanos en Francia se establecieron solamente después de la Segunda Guerra Mundial (Chonchol \& Martinière, 1985). En 1945 se inaugura la cátedra de Lenguas y literaturas de la Península Ibérica y de América Latina en el Colegio de Francia, dictada por Marcel Bataillon (Annuaire du Collège de France, 2013). En 1954, se creó el Instituto de Altos Estudios de América latina (IHEAL). Durante esta segunda etapa del hispanismo francés, la revolución cubana y la década de efervescencias revolucionarias latinoamericanas (19601970), suscitó un fuerte interés en les investigadores franceses por la región. Así es como entre 1970 y 1990 se defendieron casi 2500 tesis sobre América Latina (Mona Huerta, 2013). Recién a partir de ese momento la historia del subcontinente americano pasó a convertirse una disciplina universitaria. Y en 1970, François Chevalier se convirtió en el primer titular de la cátedra de Historia de América Latina en La Sorbona (París 1 Panthéon-Sorbonne).

2 En 1808, Napoleón dividió la universidad francesa en 18 "academias" o regiones administrativas en materia de educación. Ese sistema prevalece hasta hoy. 


\section{E X P E R I E N C I A S}

Estos cambios políticos y sociales tuvieron repercusiones en el hispanismo francés históricamente centrado en la literatura española y la enseñanza de la lengua castellana. Por un lado, las ciencias sociales hicieron su entrada en los estudios hispánicos bajo la apelación de cátedras de “civilización” en las que se enseña principalmente la historia de España y América Latina. Dados sus orígenes, el hispanismo francés conserva hasta hoy un sesgo netamente colonial (veáse cuadro $\mathrm{n}^{\circ} 1$ ). En términos lingüísticos, la norma que se enseña y domina es la del castellano de Castilla y León. Por otra parte, los estudios hispánicos se dividen en disciplinas jerarquizadas que van en orden de importancia de la literatura a la civilización. Estas disciplinas están, a su vez dividas en dos espacios geográficos, España e Hispanoamérica. A cada uno de ellos le corresponde el 50\% del contenido del programa de estudios de literatura y civilización. El resultado de esta organización es que, en términos generales, el estudiantado de los departamentos de español es precisamente, muy especializado en la cultura española. A esto hay que agregarle que los autores y temas estudiados han sido históricamente androcéntricos. En literatura, hasta la actualidad, pocas autoras -tanto españolas como latinoamericanas- figuran en los programas de estudios. Sophie Large, profesora de literatura en la universidad de Tours, ha hecho un estudio sobre los programas de literatura propuestos en los concursos franceses para el profesorado de español (CAPES y agregación de español) entre 1970 y 2019 (artículo en prensa, cortesía de la autora). En el CAPES, solo 3,5\% de las obras literarias propuestas tienen autoras mujeres mientras que en la agregación, el porcentaje es de 2,9\%. Por mi parte, he analizado los temas de historia propuestos en la agregación de español entre 1992 y 2019. En ese periodo, solo un tema, propuesto en 2008, integra la dimensión de género: "Mujeres y democracias: las españolas en el espacio público (1868-1978)”. Los demás tienen un perfil historiográfico bastante clásico como la Monarquía Católica (1999-2000), el Siglo de Oro (2018-2019), la Inquisición (2003-2004), la Ilustración y el liberalismo (2006-2007), el franquismo (2019-2020) o la transición española (2012-2013).

Cuadro $n^{\circ}$ 1: Cátedras del hispanismo en las universidades francesas (según disciplinas y áreas geográfıcas)

\begin{tabular}{|c|c|c|c|}
\hline $\begin{array}{l}\text { Cátedras y temas } \\
\text { de estudio }\end{array}$ & Literatura & Lengua & Civilización \\
\hline España & $\begin{array}{l}\text { Del Medioevo } \\
\text { a la literatura } \\
\text { contemporánea }\end{array}$ & $\begin{array}{l}\text { Castellano de Castilla } \\
\text { y León como norma } \\
\text { hegemónica }\end{array}$ & $\begin{array}{c}\text { Historia de España desde los } \\
\text { íberos a los años } 2000\end{array}$ \\
\hline $\begin{array}{c}\text { América Latina } \\
\text { (Hispanoamérica, } \\
19 \text { países) }\end{array}$ & $\begin{array}{l}\text { Literatura del } \\
\text { modernismo a la } \\
\text { literatura actual }\end{array}$ & $\begin{array}{c}\text { Español de América } \\
\text { visto como una } \\
\text { variante (dialectal) de } \\
\text { la norma lingüística } \\
\text { castellana }\end{array}$ & $\begin{array}{c}\text { De la historia colonial (vista } \\
\text { desde el prisma español) hasta } \\
\text { los años } 2000\end{array}$ \\
\hline
\end{tabular}

Fuente: Elaboración personal. 


\section{UNA HISTORIA DE LA MATERNIDAD EN CLAVE FEMINISTA DECOLONIAL}

La formación de historiadora que recibí en Francia siguió esa línea clásica. Los estudios de género no se habían incorporado aún en los programas de las grandes universidades francesas como la Sorbona. La historia de las mujeres no se trataba de manera profundizada, solo se evocaban algunos casos de personajes femeninos destacados -como en el caso de las mujeres movilizadas en la industria durante la Primera Guerra Mundial-o que fueron víctimas de la historia -como las violaciones de guerra o la tonsura de las colaboradoras de los nazis. En ese contexto, al momento de elegir mi tema de tesis doctoral, no dudé en orientarme a la historia de los magistrados peruanos del siglo XIX. Al terminar este trabajo me di cuenta que había adoptado una perspectiva androcéntrica y decidí cambiar de prisma y estudiar la historia de las madres y de la maternidad en el Perú. La historia de la salud tanto en Francia como en América latina, se encontraba en plena renovación, integrando las problemáticas de género en sus estudios. En cambio, los temas raciales seguían siendo un punto ciego de esta historia.

Mi aproximación a la historia de la salud de las mujeres debe mucho a la teoría feminista interseccional (Wallace, 2008) y decolonial (Lugones, 2011; Espinosa, Gómez \& Ochoa, 2014) elaborada en las Américas. Mi afirmación como feminista así como mi experiencia del parto me orientaron a interesarme en la historia de la maternidad peruana que hasta los años 2010 no había suscitado ningún trabajo académico centrado específicamente en el tema. Por un lado, las historias de la medicina se habían focalizado en las hazañas técnicas, los actores (los médicos) y/o las enfermedades físicas y su representación social (Cueto \& Palmer, 2015). Por el otro, los estudios feministas desarrollados desde las dos últimas décadas rehuían el tema de la maternidad considerada, siguiendo los preceptos de Beauvoir o de Friedan, como la principal forma de alienación de las mujeres. A partir de los años 1980, algunas historiadoras occidentales que no se reconocían en ese feminismo, liberal y universalista, empezaron a señalar que la maternidad es un asunto eminentemente político (Knibiehler, 2007). Paralelamente, a partir de los años 2000, en América Latina, varias historiadoras de la salud habían empezado a elaborar estudios sobre la partería y de las parteras (Alanís, 2009; Carrillo, 1999; Mott, 2005; Nari, 2004; Restrepo, 2006; Zárate, 2007).

Mis primeros trabajos en el tema de la maternidad se situaron en esa línea. Empecé estudiando la fundación de la Maternidad de Lima en 1826 y el nacimiento de la profesión de parteras tituladas en el Perú decimonónico (Quiroz, 2012). En estos estudios, analizaba cómo se había forjado la obstetricia peruana e ido implantando el parto hospitalario en el país. Al escribir esta historia, comencé a vislumbrar la forma en que se había establecido desde el siglo XIX un biopoder médico cuyo objetivo era intervenir en una rama de la salud ignota para los facultativos. Este poder se acompañaba de técnicas de disciplinamiento del cuerpo de las parturientas y de sus bebés, como en el caso del tacto vaginal, la posición de cúbito dorsal durante el parto o la manipulación de los recién nacidos por el personal médico (Quiroz, 2018).

A través de esta historia aparecía claramente que la maternidad y el nacimiento estaban muy lejos de ser acontecimientos repetitivos y de alguna manera a-históricos como algunos historiadores siguen viéndolos hasta hoy. De hecho el parto, su representación y su rol social así como los rituales en torno a él varían en el tiempo y en el espacio. En esta historia, las mujeres habían ocupado un lugar preponderante que se había ido perdiendo en prácticamente un siglo. En el 
caso del Perú, la aparición y el desarrollo de la obstetricia tuvieron como consecuencia la minoración de las mujeres y de sus saberes transmitidos de generación en generación. Un claro ejemplo de ello es la posición de cúbito dorsal durante el parto. En el Perú esta posición fue introducida por la partera francesa Madame Fessel en los años 1830 en la nueva Maternidad de Lima que ella dirigía. Esta forma de parir es totalmente anti fisiológica y molesta para la parturienta. Solo es cómoda para el personal de salud que puede observar el proceso del parto sin tener que encorvarse o sentarse en el piso. Pero además de ser incómoda, la posición de cúbito dorsal limita los movimientos de las parturientas durante el trabajo de parto. Éstas no pueden acompañar las contracciones ni aliviarlas con posturas diversas. En múltiples casos, esa posición genera mayor dolor favoreciendo en consecuencia el sufrimiento fetal. Por eso, en la actualidad, la OMS recomienda una mínima intervención médica en los casos de partos eutócicos. También aconseja que no se obstaculice el movimiento de las mujeres durante el trabajo de parto y que se respete el tiempo de la fisiología (OMS, 2018).

Desde su imposición en el siglo XIX, el parto medicalizado se erigió en total ruptura con las otras formas de nacer en vigencia en esa época. A pesar de la antigüedad y de su eficacia, éstas fueron tildadas de retrógradas y bárbaras. Y a medida que el parto medicalizado iba expandiéndose, pasaron a llamarse partos “tradicionales”. En el Perú, donde cerca del 60\% de la población era indígena y en un $90 \%$ rural, los nacimientos tenían lugar en las comunidades y a domicilio. En las comunidades autóctonas, el nacimiento se integra hasta hoy en una percepción holística de la vida. El periodo perinatal (gestación, parto y puerperio) reproduce el ciclo natural de la vida y se integra en él. Contrariamente a la representación del nacimiento occidental, la maternidad de las indígenas andinas y amazónicas no se vive como un momento aparte en la vida de las mujeres. Otra diferencia es que éstas son las principales actrices de este periodo, en relación íntima y simbiótica con la Pachamama. No obstante, no se las considera como individuos independientes sino como miembros de la comunidad que vela por ellas. Los nacimientos tienen lugar principalmente a domicilio, con la asistencia de familiares o de personas especializadas en partos como las parteras, les curiososes o les curanderes. En los espacios urbanos y peri-urbanos, las comadronas, recibidoras y curanderas jugaban hasta los años 1970 un papel central en la atención de salud no solo de las mujeres sino de la población en general. Tal es el caso de Dorotea Salguero (1770-1838), partera originaria de Lambayeque y radicada en Lima. Fue una curandera de gran renombre en las primeras décadas del siglo XIX, al punto que recibió el apelativo de "doctora" por la población limeña. Su fama suscitó la ira del Protomedicato que desató una intensa campaña contra ella que terminó con la condena judicial de Salguero al destierro y a no ejercer su profesión (Quiroz, 2016).

Desde esa época en efecto, las formas populares de atención de la salud fueron atacadas y aniquiladas por la medicina occidental. Los médicos peruanos, europeos y criollos, se otorgaron la misión de explorar todos los aspectos de la vida humana así como los saberes de los grupos sociales subalternos (indígenas, negres, mestizes). Decretaron que todas las formas de tratamiento de la salud provenientes de esos sectores de la población eran retrógradas y las substituyeron por las técnicas de la medicina occidental, entre ellas el parto medicalizado. Si la medicina occidental moderna fue creada y organizada por hombres que desconocían casi todo de la fisiología femenina, algunas mujeres también tomaron parte en la batalla contra la medicina llamada peyorativamente desde ese momento "tradicional” o hasta "brujería”. Tal es el caso del cuerpo 
de obstetrices (parteras tituladas) formado a partir de 1845 en el Perú. Las parteras tituladas, seleccionadas en función de sus orígenes raciales y de clase, además de sus conocimientos básicos en lectura, escritura y doctrina cristiana, sirvieron de punta de la lanza de la obstetricia peruana moderna. En efecto, en ellas recayó la misión de atender a las parturientas más necesitadas y de divulgar los preceptos del parto “moderno". Por ese motivo, la historia de la maternidad no puede estudiarse únicamente desde un punto de vista de género, sino que debe integrar también los factores de raza y clase (Quiroz, 2018).

La colonialidad es un concepto clave de las investigaciones que estoy desarrollando desde hace algunos años. Esta noción, planteada primero por Aníbal Quijano (1992) y completada por los estudios de otres investigadores, designa un patrón de poder global, instaurado en Abya Yala a partir de 1492, que categoriza y jerarquiza a los seres humanos en función de criterios de clase, raza, género y sexualidad. En materia de nacimiento, la colonialidad del poder (Quijano, 2000) se tradujo en políticas de la maternidad que separaban y siguen separando a las mujeres según sus orígenes. Así los programas de "parto con adecuación cultural” desarrollados desde principios de este milenio no pueden ser vistos solamente como una preocupación del Estado peruano por las poblaciones indígenas sino también como una biopolítica (Foucault, 1976). En efecto, en el Perú, estos programas solo se implementan en las comunidades rurales de los Andes y de la Amazonía. En otras palabras, para las mujeres blanco-mestizas y mestizas de las zonas urbanas, la única opción es el parto hospitalario mientras que se reserva el "parto con adecuación cultural” para las indígenas. La colonialidad del saber distinguió los conocimientos y las prácticas legítimas en materia de parto y de salud de las mujeres y los recién nacidos que correspondían al nacimiento medicalizado (Quiroz, 2016). Por su parte, la colonialidad del ser (Maldonado, 2007) creó una línea divisoria entre las personas, separándolas entre las que merecían el calificativo de humanas y que recibieron derechos y privilegios, y por otro lado las subalternas que no tenían acceso a esos derechos.

María Lugones (2008) perfiló esta diferenciación desde una perspectiva feminista decolonial, demostrando que la categoría "mujer” es una construcción ex nihilo impuesta por los conquistadores en Abya Yala. De hecho, varios estudios como los de Paula Gunn Allen (1986) indican que antes de la conquista, algunos pueblos originarios se desenvolvían en sociedades gino-céntricas. Existía además una gama relativamente amplia de géneros (entre tres y cinco). Según Lugones, con la colonización, esta situación cambió completamente. Se impuso el binarismo sexual y la categoría “mujer” fue exclusivamente reservada a las personas europeas de sexo femenino. Éstas heredaron los caracteres occidentales de la femineidad como la belleza, la fragilidad o la dulzura. Las demás quedaron asignadas a la categoría de "hembras", más o menos salvajes, fuertes y resistentes en función de criterios sociales y raciales. Esta clasificación de las "mujeres" tuvo repercusiones en la representación de la sexualidad y del parto como lo he analizado en mis trabajos sobre la maternidad peruana de los siglos XIX y XX. A las "hembras" (indígenas, negras y mulatas) se les atribuyeron caracteres de hipersexualización, barbarie y resistencia al dolor ( $L a$ República, 2014). Por ende, los partos de aquellas mujeres fueron considerados como cercanos a la animalidad. Esas representaciones justificaron una atención del parto diferenciada. Por un lado, las mujeres blancas y blanco-mestizas fueron consideradas como las más delicadas y aptas a la reproducción y se les otorgó el derecho de ser las "buenas madres" de los futuros ciudadanos del país. Las demás en cambio tuvieron que luchar para conservar sus formas de vivir y de parir. 
Como si esto no fuera poco, los cuerpos de las mujeres subalternas sirvieron de espacio de experimentación de las nuevas técnicas obstétricas, tales como el fórceps, la anestesia o la cesárea. En la Maternidad de Lima, donde se desarrolló la obstetricia moderna, entre 1861 y 1906, solo 5\% de las asistidas eran blancas. Para ellas además se crearon consultorios privados donde la atención era más personalizada.

Estas diferencias no se acabaron con la implantación, a finales del siglo XX, de una política nacional de salud materna e infantil. El ejemplo más emblemático de la biopolítica de la maternidad en el Perú es el caso de las esterilizaciones forzadas realizadas durante el gobierno de Alberto Fujimori. Entre 1996 y 2000, se esterilizaron más de 270000 personas, en su gran mayoría mujeres, en el marco del "Programa Nacional de Salud Reproductiva y Planificación Familiar” (PNSRPF). Este programa se implantó exclusivamente en dirección de las mujeres pobres e indígenas. Fue en efecto en las zonas rurales andinas y amazónicas de mayor pobreza, con menor acceso a la educación donde hubo mayor número de esterilizaciones (Informe final 73). Y como lo señalan diferentes comisiones investigadoras nombradas por el propio gobierno peruano, las tasas más elevadas de intervenciones no tomaron en cuenta el consentimiento de las mujeres y respondieron más bien a cuotas impuestas por el ministerio de salud en coordinación con la presidencia de la República (Minsa, 2002). El PNSRPF se concentró así en los vientres de las mujeres que seguían siendo animalizadas y a las que se les decía que "parían como cuyes o como chanchos" (La República, 2014). En otras palabras, este programa no fue una excepción sino un episodio más de las biopolíticas de la maternidad instauradas en el Perú desde el siglo XIX.

La perspectiva feminista decolonial me permitió reorientar mis trabajos universitarios pero también tener una comprensión distinta de la colonialidad presente en la universidad. En Francia, contrariamente a otros países, la universidad-sobre todo los establecimientos situados en ciudades pequeñas como la de Ruan donde ejerzo- tienen una composición social muy variada, con un importante porcentaje de estudiantes de clases medias bajas o hasta populares. El estudiantado es consciente de su estatus y considera la universidad como una posibilidad de ascensión social. Esto produce una cierta docilidad en él y una primacía de la posición del profesorado. Al tomar consciencia de todos estos parámetros, se hacía necesaria reevaluar también la pedagogía.

\section{PROPUESTAS PEDAGÓGICAS}

La perspectiva feminista invita no solo a replantear la problemática de estudio sino también las prácticas pedagógicas. En ese sentido, combinar investigación y enseñanza es un ejercicio sumamente estimulante. En mi caso, a esas dos actividades profesionales se les agregan charlas y discusiones en colectivos feministas y antirracistas franceses. Me sitúo así en la larga tradición latinoamericana de pedagogías emancipadoras asociadas a nombres como los de José Martí, José Carlos Mariátegui o Paulo Freire, pero también desarrolladas en el marco de proyectos educativos revolucionarios (Cuba, Nicaragua) o más recientemente en el Movimiento de los Sin Tierra brasileño, la universidad Amawtay Wasi en Ecuador o el Sistema de Educación Rebelde zapatista. En esa línea, me interesa sobre todo romper con los clichés que reducen Latinoamérica a lo exótico y subalterno en los espacios universitarios y militantes franceses. 
En primer lugar, se trata de invitar al estudiantado de primer ciclo universitario - principalmente femenino en mi facultad- a cambiar de prisma al abordar la historia desde una perspectiva feminista decolonial. Eso significa movilizar conceptos como "género", "sexualidad", "colonialidad" o "Abya Yala” entre otros. Es necesario presentarlos y explicarlos pero también integrarlos en las diferentes sesiones de manera dinámica tanto en el contenido como en la práctica. Un ejemplo concreto puede verse en el tema dedicado a las independencias latinoamericanas. Pocas facultades francesas proponen el tema en el programa de estudios de civilización o de historia latinoamericana. Y cuando se aborda dicha temática, se pone de relieve la acción de los hombres criollos como Hidalgo, San Martín, Bolívar o Santa Cruz en la perspectiva de una historia social de las élites latinoamericanas. Estos personajes aparecen como los representantes de pueblos que se rebelan en medio de la crisis de la monarquía española y las independencias derivan de su incapacidad a responder a sus demandas. Los espacios centrales de estos estudios siguen siendo generalmente los virreinatos que prefiguran los Estados nacionales y las capitales.

Mi forma de abordar este periodo es distinta. Me interesa mostrar más bien cómo esta historiografía no es neutra: fue escrita y en muchos casos sigue siéndolo desde el punto de vista de las élites y del poder. La actuación de les subalternes en los procesos de independencia ha quedado de esta manera invisibilizada. La fuerza y la labor política de las mujeres en general y de las indígenas en particular no figuran por ejemplo en esta historiografía. En muchos casos, cuando las mujeres aparecen en la historia de las independencias, lo hacen en calidad de "compañeras de”. Ahora bien sabemos por el contrario que éstas jugaron un papel central en las rebeliones anticoloniales como lo prueba la acción de mujeres como Bartolina Sisa, Gregoria Apaza o Micaela Bastidas a finales del siglo XVIII. Lo mismo sucede con las insurrecciones y resistencia de los esclavos y afrodescendientes. Les estudiantes ignoran así la existencia de los palenques y quilombos. El palenque de San Basilio en Colombia fue sin embargo uno de los lugares de resistencia antiesclavista más importantes de Sudamérica. Por otra parte, casi nunca se evoca en los estudios secundarios la importancia de la revolución de Haití, a pesar de haber sido una colonia francesa. La rebelión de Santo Domingo fue sin embargo una verdadera revolución decolonial que replanteó las estructuras del poder en la isla (Girard, 2013). Por primera vez en el continente, un grupo de esclaves y afrodescendientes expulsó a los colonizadores y fundó en 1804 la primera República negra del planeta. Tanto en las Américas, como en Francia, esta revolución ha sido minorada y hasta cierto punto deslegitimada al insistir los historiadores en su carácter extremadamente violento (en particular las masacres de blancos). Desde una perspectiva feminista decolonial, me parece importante resaltar acontecimientos como los evocados en este párrafo sin por ello dejar de presentar a los personajes y hechos más conocidos, situando a cada uno en su lugar de enunciación. El objetivo es mostrar la diversidad de actuaciones y de puntos de vista sin sobrevalorar la historiografía que ensalza la acción de los hombres criollos.

El desequilibrio en la enseñanza de la historia se observa también en la bibliografía movilizada para estudiar los diferentes temas de los programas. Desde los años 1970, las feministas occidentales que ingresaron a la universidad cuestionaron el carácter androcéntrico del material bibliográfico propuesto en las clases universitarias. Desde entonces empezaron a escribir y recopilar textos con prisma de género. Poco a poco, historiadoras como Michelle Perrot, Joan W. Scott, Mary Nash, Mary Beard, Marie-Jo Bonnet, Cándida Martínez López o Dora Barrancos fueron haciéndose un lugar en el espacio académico occidental. Las voces del feminismo decolo- 
nial como Ochy Curiel o Yuderkys Espinosa denuncian sin embargo que estas mujeres europeas, blancas o blanco-mestizas y de clases medias y superiores, solo visibilicen y escriban la historia del feminismo occidental y burgués. Por eso las bibliografías decoloniales buscan poner de relieve la documentación y la teoría producida desde el sur global, principalmente las de las mujeres. Ahora bien, ya sea por factores económicos, educativos o de acceso al mundo académico y de la edición, pocas personas subalternas publican textos en revistas indexadas. En consecuencia, esta situación invita a revisar la relación de les historiadores con la bibliografía tanto secundaria como primaria.

En lo que respecta a esta última, debido a su origen europeo, la historia académica le atribuye un papel central a las fuentes escritas. Los archivos siguen siendo la base principal del trabajo histórico. En el contexto europeo donde la documentación ha sido recopilada y conservada desde hace muchos siglos, esta forma de abordar la historia se justifica y funciona bastante bien. Muy diferente es la situación en espacios como el Perú, donde escasean los documentos escritos, más aún en lenguas indígenas. En ese sentido son sumamente interesantes las iniciativas que valorizan la historia oral. Tal es el caso del Seminario de Historia Rural Andina fundado por el historiador Pablo Macera en el Perú en 1966 y el Taller de Historia Oral Andina (THOA), propulsado en Bolivia desde 1983 por Silvia Rivera Cusicanqui. Estos organismos buscaban romper con la primacía de la historia criolla y dar mayor visibilidad a la agencia y empoderamiento indígenas en la historia contemporánea de estos países. Esta forma de abordar la historia -aún la contemporánea-despierta cierto recelo en la comunidad historiadora francesa que sigue poniendo en un pedestal los archivos y las fuentes escritas. En mi caso, he podido esquivar esta limitación gracias al hecho que me desenvuelvo en una facultad de lenguas y no de historia donde sería más complicado enseñar otras epistemologías y métodos de abordar la historia. En Francia, las cátedras de "civilización” permiten integrar a la historia diferentes epistemologías disciplinarias (sociología, geografía, antropología y ciencias políticas) así como las postcoloniales y decoloniales.

Precisamente, el hecho de desempeñar mi oficio en un departamento de estudios hispánicos me lleva a prestar una atención especial a la lengua española. Además de enseñar al estudiantado las bases lingüísticas de nuestro idioma, me interesa mostrar cómo este es también un vector de poder. Como ya lo señalé en la primera parte, en Francia la norma hegemónica es la del castellano español. Siendo la única profesora titular de origen latinoamericano, considero que parte de mi misión es también mostrar la riqueza, la variedad y la importancia del castellano hablado en las Américas. Me parece además importante porque muchas de las estudiantes de nuestro departamento siguen la formación y la preparación a los concursos para convertirse en profesores de primaria y secundaria. Por otra parte, como feminista, considero además que la norma del lenguaje que empleamos tanto en francés como en castellano es androcéntrica y contribuye a la perpetuación de la dominación masculina. Diversas instituciones reaccionarias que se consideran como guardianas del templo, tales como la Real Academia Española de la Lengua o la Academia Francesa, rechazan firmemente el lenguaje inclusivo. En el plano académico, hay todavía esfuerzos por realizar en ese sentido, pues pocas editoriales o revistas han adoptado el lenguaje no sexista. En respuesta a ello, me parece importante resaltar las iniciativas en favor del lenguaje incluyente que existen en ambos lados del Atlántico. Un primer paso en la construcción de relaciones sin opresión ni jerarquía de poder, es hacer tomar conciencia de lo que implica en términos de representación social y de precisión como 
historiadores, emplear palabras como "los presidentes", "los obreros" o "las enfermeras". En un segundo momento, me parece apropiado convocar a las propuestas del alumnado y en última instancia proponer las diferentes formas de resolver los problemas planteados hoy por el lenguaje sexista heredado del siglo XIX. La comparación entre las soluciones propuestas en Francia como en América Latina permite además comprender la importancia del contexto y de la historia de cada lengua.

En términos más concretos, otro tema importante es el de la evaluación. Diferentes estudios (Antibi, 2003, Fabre, 2015) muestran que las notas no constituyen una forma neutra ni objetiva de evaluación -aun cuando los exámenes son anónimos. Les docentes tienden a poner notas en función de parámetros subjetivos que terminan por discriminar a les estudiantes más frágiles. Un método alternativo es "la evaluación por contrato de confianza" (EPCC) que busca romper con la "constante macabra”, es decir la propensión de les profesores de calificar con notas bajas una misma proporción de exámenes, sea cual sea la prueba. La EPCC propone anunciar claramente y con anticipación la fecha de evaluación, el programa de revisión (accesible a les alumnes), la(s) pregunta(s) que se van a proponer, el baremo de la evaluación que contemple un máximo de 4 puntos sobre 20 para una pregunta que no figure en el programa de revisión (Antibi, 2007). Los resultados que he observado en la aplicación de este método son una mejor asimilación del programa de estudios y una mayor confianza de les estudiantes en elles mismes.

Por último, considero primordial hacer un esfuerzo en descolonizar el saber académico a través de un esfuerzo vulgarizador en el sentido noble de la palabra. Diversas autoras feministas interseccionales y decoloniales señalan cómo la universidad occidental fomenta la distinción a través del empleo de un lenguaje y de referencias desconocidas e inaccesibles a la mayoría de la población. Ya en 1984 bell hooks planteaba la cuestión en los siguientes términos:

The ability to "translate" ideas to an audience that varies in age, sex, ethnicity, degree ofliteracy is a skill feminist educators need to develop. Concentration of feminist educators in universities encourages habitual use of an academic style that may make it impossible for teachers to communicate effectively with individuals who are not familiar with either academic style or jargon. All too often educators, especially university professors, fear their work will not be valued by other academics if it is presented in a way that makes it accessible to a wider audience. If these educators thought of rendering their work in a number of different styles, "translations", they would be able to satisfy arbitrary academic standards while making their work available to masses people. (hooks, 1984, p. 111)

En total acuerdo con bell hooks considero necesario para el feminismo reconsiderar la relación con los "márgenes", es decir, con los saberes y las personas considerados como subalternos. El sistema universitario global pone a al personal académico en un espacio de superioridad, el punto cero evocado por Castro-Gómez (2007). Esto lo lleva en muchos casos a enaltecer a autores ya consagrados y/o que se desenvuelven en universidades prestigiosas como si fueran las únicas referencias legítimas. Y al mismo tiempo se puede tender a minorar los saberes y las referencias populares. En mi experiencia, el estudiantado posee saberes en diferentes campos pero se autocensura por considerarlos ilegítimos asumiendo en muchos casos una posición úni- 


\section{E X P E R I E N C I A S}

camente receptora y pasiva. En Francia, el alumnado de las universidades regionales públicas no pertenece a las clases adineradas sino que tiene una base de clases medias bajas y populares. Romper esa jerarquía e instaurar una confianza para expresarse, son tareas docentes que a mi parecer no deben descuidarse. La instauración de un clima benevolente pasa por la distribución espacial del salón de clase - privilegiar la instalación de les participantes en círculo por ejemplo. Es difícil contrarrestar el peso de las estructuras institucionales. Pero hay que aprovechar todos los intersticios de libertad para desarrollar la agencia de todes les actores educatives.

\section{CONCLUSIÓN}

En suma, el prisma feminista decolonial promueve una mirada crítica de la colonialidad del saber. Este concepto pone de relieve la desigualdad y las relaciones de poder que se ejercen en torno al conocimiento y la educación. En el centro de este sistema se encuentran las universidades del norte global que gozan de una importante financiación y del prestigio de sus catedráticos como de sus producciones intelectuales generalmente clasificadas en los rankings internacionales como el de Shanghái. En la periferia de este círculo de elegidos se encuentran las universidades de los espacios subalternos. Descolonizar el saber significa romper esa jerarquía y revalorar los saberes -académicos y externos- situados en las márgenes desde la creación misma de las universidades.

En términos de los saberes sobre el parto y la maternidad, la perspectiva feminista decolonial me ha llevado a centrarme más en los procesos de diferenciación de las mujeres en función de su clase y raza, atribuyéndoles representaciones estereotípicas que se traducen en regímenes políticos de la maternidad distintos. En lo que a la enseñanza de la historia respecta, esta perspectiva invita a disolver las jerarquías tanto en el contenido de los cursos como en las prácticas pedagógicas. Aunque la universidad sea uno de los espacios más emblemáticos de la colonialidad, es necesario no dejarla de lado en los procesos de disolución de las jerarquías y de instauración de relaciones más igualitarias. En este movimiento, la historia juega un papel central pues permite comprender cómo se construyó la colonialidad en medio de espacios con cosmovisiones distintas y desde entonces minoradas. Como lo señala Boaventura de Sousa Santos (2018), el desafío de la universidad del siglo XXI es grande pues "para mantener su identidad como bien común, la universidad tiene que transformar muchas de sus ideas del pasado. Entonces ya no va a ser una universidad, va a ser una pluriversidad”.

\section{REFERENCIAS}

Alanís Rufino, M. (2009). Una cuestión de parteras y médicos. Mujeres en el Hospital de la Maternidad e Infancia en la Ciudad de México, 1861-1905. Boletín Mexicano de Historia y de Filosofía de la Medicina, (12/2), pp. 63-68.

Annuaire du Collège de France. (2013). Tableau des chaires depuis 1800. Annuaire du Collège de France, 112 , pp. 23-57.

Antibi, A. (2003) La constante macabre ou comment a-t-on découragé des générations d'élèves? Paris: Math'Adore. 


\section{E X P E R I E N C I A S}

-. (2007). Pour en finir avec la constante macabre ou Les Notes: La fin du cauchemar, Antibi.

Anzaldúa, G. (1987). Borderlands. La Frontera. The New Mestiza. San Francisco: Spinsters, Aunt Lute.

Carrillo, A. M. (1999). Nacimiento y muerte de una profesión. Las parteras tituladas en México. Dynamis (Granada), (19), pp. 67-190.

Castro-Gómez, S. (2005). La hybris del punto cero: ciencia, raza e ilustración en la Nueva Granada (17501816). Bogotá: Editorial Pontificia Universidad Javeriana.

Chonchol, J. \& Martinière, G. (1985). L'Amérique latine et le latino-américanisme en France. París: L'Harmattan.

Cirot, G. (1899). Les études hispaniques à l'université de Bordeaux. Bulletin hispanique (1-4), pp. 255-264.

Cueto, M. \& Palmer, S. (2015). Medicine and Public Health in Latin America: A History. New York: Cambridge University Press.

Espinosa-Miñoso, Y. (2014). Una crítica descolonial a la epistemología feminista crítica. El Cotidiano (184, mar.-abr.), pp. 7-12.

Espinosa-Miñoso, Y., Gómez Correal, D. \& Ochoa Muñoz, K. (Ed.) (2014). Tejiendo de otro modo: Feminismo, epistemología y apuestas descoloniales en Abya Yala. Popayán: Ed. Univ. del Cauca.

Favre, D. (2015). Cessons de démotiver les élèves. París: Dunod.

Foucault, M. (1997). Cours du 17 mars 1976. Ewald, F., Fontana, A. (Ed.). Il faut défendre la société: cours au Collège de France, 1975-1976. París: Seuil.

Girard, P. R. (2011). The slaves who defeated Napoléon.Toussaint Louverture and the Haitian War of Independence, 1801-1804, Tuscaloosa: The University of Alabama Press.

Gunn Allen, P. (1986). The Sacred Hoop: Recovering the Feminine in American Indian Traditions. Boston: Beacon Press.

hooks, b. (2007). El feminismo es para todo el mundo. Madrid: Traficantes de sueños.

—. (1984). Feminist Theory. From Margin to Center. Boston: South End Press.

Huerta, M. (2013). Le latino-américanisme français en perspective. Caravelle (Toulouse) (100), pp. 39-62.

Informe final sobre la aplicación de la anticoncepción quirúrgica voluntaria (AQV) en los años 1990-2000. (2002). Lima. URL: https://bit.ly/2nYx8Od (consultado el 08/08/19).

Jaquet, C. (2015). Los transclase. Entrevista con Chantal Jaquet”. Humanité Dimanche, 5 de feb. URL : https://bit.ly/21SinMo (consultado el 08/08/19).

Knibiehler, Y. (2007). Qui gardera les enfants? Mémoires d'une féministe iconoclaste. París: Calmann-Lévy.

Lugones, M. (2011). Hacia un feminismo descolonial. La manzana de la discordia. (vol. 6, n² 2), pp. 105-119.

-. (2008). Colonialidad y género. Tabula Rasa. Bogotá (9, jul.-dic), pp. 73-101.

Maldonado-Torres, N. (2007). Sobre la colonialidad del ser: contribuciones al desarrollo de un concepto. In: Castro-Gómez, Santiago; Grosfoguel, R. (Ed.). El giro decolonial. Reflexiones para una diversidad epistémica más allá del capitalismo global. Bogotá: Iesco-Pensar-Siglo del Hombre Ed., pp. 127-167. 


\section{E X P E R I E N C I A S}

Mignolo, W. (2003). Historias locales/diseños globales: colonialidad, conocimientos subalternos y pensamiento fronterizo. Madrid: Akal.

Ministerio de Salud (Minsa). (2002). Informe sobre la campaña de sensibilización del Plan de emergencia AQV en las localidades de Sayán y Oyón. Lima. URL: https://bit.ly/2nW2gOm (consultado el 08/08/19).

Mott, M. L. (2005). Parteiras: o outro lado da profissão. Noterói (sem. 2, v. 6, n 1), pp. 117-140.

Nari, M. (2004). Politicas de maternidad y maternalismo político. Buenos Aires, 1890-1940. Buenos Aires: Biblos.

OMS. Individualized, supportive care key to positive childbirth experience, says WHO, 15 feb. 2018. URL: https://bit.ly/2HhXggf (consultado el 08/08/19).

Perrot, M. (2006). Mon histoire des femmes. París: Ed. Seuil.

Quijano, A. (2000). Colonialidad del poder, eurocentrismo y América Latina. In : Lander, E. (Comp.). La colonialidad del saber: eurocentrismo y ciencias sociales. Perspectivas Latinoamericanas. Buenos Aires: Clacso, pp. 201-246.

Quiroz, L. (2018). Dar a luz en el Perú. La partería en la encrucijada de las biopolíticas de medicalización del parto, siglos XIX a XXI. Sánchez, G. \& Laako, H. (Ed.). Parterías de Latinoamérica. Diferentes territorios, mismas batallas, San Cristóbal de Las Casas, Chiapas, Mexico : El Colegio de la Frontera Sur, pp. 70-93.

- (2016). Descolonizar el saber médico. Obstetricia y parto en el Perú contemporáneo (siglos XIX y XX). Revue d'Études Décoloniales, nº 1, oct. URL : http://reseaudecolonial.org/822-2/

-. (2012). De la comadrona a la obstetriz. Nacimiento y apogeo de la profesión de partera titulada en el Perú (siglo XIX). DYNAMIS. Acta Hispanica ad Medicinae Scientiarumque Historiam Illustrandam (Granada), 32 (2), pp. 415-437.

Restrepo, L. J. (2006). Médicos y comadronas o el arte de los partos. La ginecología y la obstetricia en Antioquia, 1870-1930. Medellín: La Carreta Ed.

Rivera Cusicanqui, S. (2010). Ch'ixinakax utxiwa: una reflexión sobre prácticas y discursos descolonizadores. Buenos Aires: Tinta Limón.

Spivak, G. (1988). Can the Subaltern Speak? Basingstoke: Macmillan.

Souza Santos, B. (2018). La universidad puede ser un campo para articular la resistencia. La Tinta, 19 de junio. URL: https://bit.ly/2nsuq3a (consultado el 08/08/19).

(2014). Ustedes paren como cuyes, como chanchos.... La República, 27 de enero. URL: https://bit. ly/2nYXFek (consultado el 08/08/19).

Wallace, M., Combahee River Collective, Lorde, Audre y al. (2008). Blackfeminism: anthologie du féminisme africain-américain, 1975-2000. París: L’Harmattan.

Zárate Campos, M. S. (2007). Dar a luz en Chile, siglo XIX. De la "ciencia hembra" a la ciencia obstétrica, Ed. Univ. Alberto Hurtado, Centro de Investigaciones Diego Barros Arana. 